\title{
Erratum to: Self-efficacy mediates the relationship between behavioral processes of change and physical activity in older breast cancer survivors
}

\author{
Paul D. Loprinzi · Bradley J. Cardinal
}

Published online: 15 November 2011

(C) The Japanese Breast Cancer Society 2011

\section{Erratum to: Breast Cancer \\ DOI 10.1007/s12282-011-0298-x}

The original version of this manuscript failed to include Dr. Kerri Winters-Stone as the last author, who heretofore, should be considered as last author on the manuscript. Additionally, the article failed to acknowledge its funding source: 1R01 CA120123 awarded to, Dr. Winters-Stone, Principal Investigator. Lastly, we wish to make clear that the article was based upon a secondary data analysis using data from a larger randomized clinical trial. Accordingly, the following additional detail to the methods warrants inclusion: (1) the sample consists of participants who had completed a 12-month randomized, controlled trial of structured exercise; (2) the 69 participants in the study included $60 \%$ of the baseline sample from the randomized, controlled trial (69/114); (3) these data were collected at the end of the trial as participants transitioned to a selfsupported exercise environment; (4) all testing procedures were conducted at Oregon Health \& Science University in Portland, OR, USA; and (5) all questionnaire-derived data were obtained at four time periods: baseline of the randomized trial, 6 months into the trial, at the conclusion of the trial (12-month period), and 6 months following the trial.

The online version of the original article can be found under doi:10.1007/s12282-011-0298-x.

P. D. Loprinzi $(\square)$

Department of Exercise Science, Donna and Allan Lansing

School of Nursing and Health Sciences, Bellarmine University,

Louisville, KY 40205, USA

e-mail: ploprinzi@bellarmine.edu

B. J. Cardinal

Program of Exercise and Sport Science,

School of Biological and Population Health Sciences,

College of Public Health and Human Sciences,

Oregon State University, Corvallis, OR, USA 